\title{
Increased susceptibility of algal symbionts to photo-inhibition resulting from the perturbation of coral gastrodermal membrane trafficking
}

\author{
CHEN Chii-Shiarng ${ }^{1,2,3}$, YEH Shih-Pin ${ }^{2}$, WANG Li-Hsueh ${ }^{1,2}$, LI Hsing-Hui ${ }^{1,2}$ \& CHEN Uang Wan-Nan ${ }^{4 *}$ \\ ${ }^{1}$ Taiwan Coral Research Center, "National" Museum of Marine Biology \& Aquarium, Pingtung 944, Taiwan, China; \\ ${ }^{2}$ Institute of Marine Biotechnology, "National" Dong Hwa University, Pingtung 944, Taiwan, China; \\ ${ }^{3}$ Department of Marine Biotechnology and Resources, "National" Sun Yat-Sen University, Kaohsiung 804, Taiwan, China; \\ ${ }^{4}$ Department of Biological Science and Technology, I-Shou University, Kaohsiung 824, Taiwan, China
}

Received March 14, 2012; accepted May 9, 2012

\begin{abstract}
The stability of cnidarian-dinoflagellate endosymbioses is dependent upon communication between the host gastrodermal cell and the symbionts housed within it. Although the molecular mechanisms remain to be elucidated, existing evidence suggests that the establishment of these endosymbioses may involve the sorting of membrane proteins. The present study examined the role of host gastrodermal membranes in regulating symbiont (genus Symbiodinium) photosynthesis in the stony coral Euphyllia glabrescens. In comparison with the photosynthetic behavior of Symbiodinium in culture, the Symbiodinium populations within isolated symbiotic gastrodermal cells (SGCs) exhibited a significant degree of photo-inhibition, as determined by a decrease in the photochemical efficiency of photosystem II $\left(F_{\mathrm{v}} / F_{\mathrm{m}}\right)$. This photo-inhibition coincided with increases in plasma membrane perturbation and oxidative activity in the SGCs. Membrane trafficking in SGCs was examined using the metabolism of a fluorescent lipid analog, $N$-[5-(5,7-dimethyl boron dipyrromethene difluoride)-1-pentanoyl]-D-erythro-Sphingosylphosphorylcholine (BODIPY-Sphingomyelin or BODIPY-SM). Light irradiation altered both membrane distribution and trafficking of BODIPY-SM, resulting in metabolic changes. Cholesterol depletion of the SGC plasma membranes by methyl- $\beta$-cyclodextrin retarded BODIPY-SM degradation and further augmented Symbiodinium photo-inhibition. These results indicate that Symbiodinium photo-inhibition may be related to perturbation of the host gastrodermal membrane, providing evidence for the pivotal role of host membrane trafficking in the regulation of this environmentally important coral-dinoflagellate endosymbiosis.
\end{abstract}

\section{Cnidaria, endosymbiosis, fluorescent lipids, lipid trafficking, PAM, photosynthesis, Symbiodinium}

Citation: Chen C S, Yeh S P, Wang L H, et al. Increased susceptibility of algal symbionts to photo-inhibition resulting from the perturbation of coral gastrodermal membrane trafficking. Sci China Life Sci, 2012, 55: 599-611, doi: 10.1007/s11427-012-4345-4

Cnidarian-dinoflagellate endosymbioses, in which gastrodermal cells of the host animal harbor photosynthetic dinoflagellates (i.e., Symbiodinium sp.), are of mutual benefit to both partners, yet are prone to disintegration upon prolonged exposure to environmental changes [1]. The cellular and molecular mechanisms underlying the establishment, persistence, and breakdown of these endosymbioses remain

*Corresponding author (email: wendyuchen@isu.edu.tw) to be elucidated. Further research should seek to investigate two important pathways, in particular, to increase the overall level of understanding of these ecologically important, environmentally sensitive associations.

First, the plasma membrane of the host gastrodermal cells represents a pivotal structural and functional component in the symbiotic process. Endosymbiosis is initiated by the phagocytosis of Symbiodinium into gastrodermal cells as shown in Hydra viridis [2], and the initial membrane of the 
phagosome containing the Symbiodinium cell is derived from the host plasma membrane. The host plasma membrane then develops into the symbiosome membrane, which protects the Symbiodinium from digestion by the host. Although the nature of the membrane modifications occurring during this process remains unclear, existing data indicate that membrane protein sorting may be involved. Immunofluorescence investigations of the initial stages of the Aiptasia pulchella (anthozoan sea anemone)-Symbiodinium association indicate that the small GTPase Rab-7, a late endosome-specific membrane protein, is sorted away from the symbiosome membrane or phagosome membrane containing live Symbiodinium [3]. However, most phagosomes containing either heat-killed or photosynthetically-impaired Symbiodinium tested positive for Rab-7. These data indicate that development and regulation of endosymbiosis involves highly coordinated membrane trafficking between the host plasma membrane, the phagosome membrane, and the symbiosome membrane [4].

A more thorough understanding of the molecular regulation of photosynthesis in these associations would also allow for a more comprehensive understanding of these mutualisms from a mechanistic perspective. Symbiodinium photosynthesis is arguably at the metabolic core of the cnidarian-dinoflagellate endosymbioses, as Symbiodinium translocate up to $95 \%$ of the carbon they fix to their hosts [5]. Interestingly, the Symbiodinium photosynthetic apparatus has been shown to be readily photoinhibited in response to even slight changes in the abiotic environment $[6,7]$. As such, decreases in photochemical efficiency and, consequently Symbiodinium carbon fixation, are often documented in stressed and bleaching cnidarians [8]. Given the correlation between photo-inhibition and the degree of stress experienced by the cnidarian-dinoflagellate "holobiont," photochemical efficiency measurements have been used as an early warning indicator of bleaching [9]. Upon exposure to elevated temperatures at various light intensities, it was found that the host cell plays a significant role in determining the bleaching susceptibility of corals [9], indicating that symbiont photosynthesis is regulated by host gastrodermal cells. However, the mechanism of this regulation remains to be elucidated.

Intriguingly, it has been shown that the coral-dinoflagellate holobionts are more sensitive to changes in UV irradiation in comparison to free-living dinoflagellates and Symbiodinium-free corals [10]. Excessive UV irradiation incites a higher level of DNA breakage in the holobiont, which can result in bleaching. Elevated levels of irradiation may also damage membrane lipids through the effect of reactive oxygen species (ROS) [11-13]. Specifically, past studies have shown that Symbiodinium thylakoid membrane lipids are damaged in corals undergoing thermal stressinduced bleaching [14]. These authors found that different lipid ratios of various Symbiodinium clones correlated with their response to environmental stress, as reflected by photochemical efficiency changes. Consequently, it is highly possible that irradiation may not only affect photosynthesis, but also perturb the membrane composition or metabolism in both components of the cnidariandinoflagellate holobiont.

How changes in membrane trafficking within the holobiont affect the stability of cnidarian-dinoflagellate endosymbioses remains totally unexplored. The present study hypothesizes that the host gastrodermal plasma membrane and its lipid trafficking may have a significant impact on Symbiodinium photosynthesis. Specifically, light irradiation treatment will directly affect the structure and composition of the gastrodermal plasma membrane. This change in membrane composition may directly affect the lipid trafficking that modifies the symbiosome membranes, which would then influence physiological processes within Symbiodinium, such as photosynthesis [4]. To investigate whether there is direct interaction between the host membrane and the resident Symbiodinium populations, this study first isolated symbiotic gastrodermal cells (SGCs, i.e., gastroderm cells with intracellular Symbiodinium) from Euphyllia glabrescens using a noninvasive method. Then, using a combination of single-cell Pulse Amplitude Modulated (PAM) microscopy, quantitative fluorescence microscopy, and lipid analyses, two questions were asked: (i) How does light influence the maximum Symbiodinium photochemical efficiency in SGCs? (ii) How do changes in the membrane trafficking of SGCs correlate with the photochemical efficiency of their resident Symbiodinium?

\section{Materials and methods}

\subsection{Reagents, culture media and filtered seawater}

The fluorescent lipid analogue, $N$-[5-(5,7-dimethyl boron dipyrromethene difluoride)-1-pentanoyl]-D-erythro-sphingosylphosphorylcholine (BODIPY-SM) complexed with de-fatted bovine serum albumin (DF-BSA) and Iscove's Modified Dulbecco's Medium (IMDM) with $\mathrm{NaHCO}_{3}$ were purchased from Invitrogen (Carlsbad, CA, USA). The IMDM solution for cell treatment was prepared by addition of both $10 \%$ fetal bovine serum and antibiotics (streptomycin, $100 \mu \mathrm{g} \mathrm{mL}^{-1}$; penicillin, 100 units $\mathrm{mL}^{-1}$ ). Poly-L-Lysine solution $(0.1 \% \mathrm{w} / \mathrm{v}$ in water) was obtained from Sigma-Aldrich (St. Louis, MO, USA). All seawater used in the experiments was prepared by filtering through a VacuCap® 90 filter unit $(0.2 \mu \mathrm{m}$, Pall Gelman Laboratory, Ann Arbor, MI, USA). The osmolarity of all solutions used for cell treatment was measured using a micro-osmometer (Advanced Instruments, Inc., Norwood, MA, USA), and, when necessary, solutions were adjusted to $1000 \mathrm{mOsmol}$ by addition of $\mathrm{NaCl}$. All chemicals were of analytical grade. 
1.2 Coral collection and preparation of "inside-out" tentacles and symbiotic gastrodermal cells (SGC)

Colonies of the reef-building coral Euphyllia glabrescens were collected by SCUBA divers at Houwan, South Taiwan $\left(21^{\circ} 57^{\prime} 22.56^{\prime \prime} \mathrm{N}, 120^{\circ} 45^{\prime} 17.46^{\prime \prime} \mathrm{E}\right)$. Colonies were immediately transferred in seawater-filled coolers to Taiwan's National Museum of Marine Biology and Aquarium, placed in an upright position in an outdoor aquarium with flowthrough seawater (exchange rate $\sim 2 \%$ per hour), and left to recover before use. The "inside-out" manipulation of amputated tentacles and isolation of symbiotic gastrodermal cells (SGCs) were performed according to a published procedure [15]. Intactness of the gastrodermal cell membranes in the SGCs was then examined sensu [15]. Cells were suspended in filtered seawater (FSW) at a final concentration of $\sim 1 \times 10^{6}-2 \times 10^{6} \mathrm{~mL}^{-1}$ and were immediately used for experiments.

\subsection{Clade identification of Symbiodinium in hospite and the culture of free-living clade $\mathrm{C} 1$ Symbiodinium}

Endosymbiotic Symbiodinium sp. were directly isolated from E. glabrescens according to a published procedure [16] and identified according to their internal transcribed spacer (ITS) rDNA sequence sensu [16]. Briefly, DNA was first extracted using a ZR Plant/Seed DNA Kit (Zymo Research, Orange, CA, USA) following the manufacture's instructions. The extracted DNA was amplified using $1 \times$ AccuPrime PCR buffer, $200 \mathrm{nmol} \mathrm{L}^{-1}$ primers [17] and $5 \mathrm{U}$ AccuPrime $\mathrm{PfX}$ (Invitrogen) in a $50 \mu \mathrm{L}$ polymerase chain reaction (PCR). The forward and reverse primers were 5'-CCGGTGAATTATTCGGACTGACGCAGT-3' and 5'-TVVTVVGVTTATTGATATGV-3', respectively. After an initial denaturation at $94^{\circ} \mathrm{C}$ for $5 \mathrm{~min}, 35$ cycles were conducted at $94^{\circ} \mathrm{C}$ for $30 \mathrm{~s}, 50^{\circ} \mathrm{C}$ for $30 \mathrm{~s}$, and $72^{\circ} \mathrm{C}$ for $60 \mathrm{~s}$. Finally, an additional elongation step was carried out at $72^{\circ} \mathrm{C}$ for 10 min. The PCR products were resolved on $1 \%$ TBE-agarose gels with ethidium bromide staining. The 762 bp amplicon was purified using the Axygen DNA Gel Extraction Kit (Axygen Biosciences, Union City, CA, USA) according to the manufacturer's recommendations and then cloned with the PCR-Blunt II TOPO cloning kit (Invitrogen) according to the manufacturer's recommendations. Select clones were sequenced on the ABI 3100 (Applied Biosystems, Foster City, CA, USA; manufacturer's recommendations), and the sequence obtained (accession: HQ020493) was compared with other clades of Symbiodinium in the NCBI GenBank Database with Blastn (http://www.ncbi.nlm. nih.gov/). The sequence cloned herein showed high similarity (99\% identity) with a clade C1 Symbiodinium sequence (accession: AB294654). As a consequence, a clade C1 Symbiodinium sp. culture was purchased from the Center for Culture of Marine Phytoplankton (strain CCMP 2466; West Boothbay Harbor, Maine, CA, USA) in order to have a cultured Sym- biodinium to compare against the results from Symbiodinium housed within the SGCs used in the study.

\subsection{Calcofluor White M2R staining for membrane perturbation}

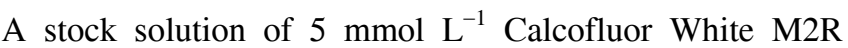
(CFW, Sigma-Aldrich) was prepared in distilled water and stored at $4^{\circ} \mathrm{C}$ in the dark before use. Cells were treated with $50 \mu \mathrm{mol} \mathrm{L}{ }^{-1} \mathrm{CFW}$ in FSW at room temperature for 30 min. They were then washed with FSW and loaded onto a polylysine-coated glass cover slip for cells to settle. The slip with the stained cells was then mounted, and the CFW fluorescent staining was examined by fluorescence microscopy.

\subsection{Quantitative microscopic measurement of cellular reactive oxygen species (ROS) in SGCs}

The effect of light on oxidation state in SGCs was examined by quantitative microscopy using the cell permeable fluorogenic indicator $2^{\prime}, 7^{\prime}$-dichlorodihydrofluorescein diacetate ( $\mathrm{H}_{2} \mathrm{DCFDA}$ ) (Invitrogen), as modified from published procedures $[15,18,19] . \mathrm{H}_{2}$ DCFDA has been widely used to detect ROS, including $\mathrm{H}_{2} \mathrm{O}_{2}$ and hydroxyl radicals, in mammalian cells, algae, and endosymbiotic dinoflagellates [19-21]. $\mathrm{H}_{2}$ DCFDA is cell permeable and once it diffuses into cells, its diacetate group is cleaved by cellular esterases, resulting in a more polar molecule (i.e., $\mathrm{H}_{2} \mathrm{DCF}$ ) with better cell retention. Then, the cellular non-fluorescent $\mathrm{H}_{2} \mathrm{DCF}$ is oxidized into fluorescent dichlorofluorescin (DCF) in proportion to the abundance of cellular ROS species.

Aliquots of SGCs suspended in FSW were first attached to poly-L-lysine-coated glass cover slips $(18 \mathrm{~mm} \times 18 \mathrm{~mm}$, Mariefeld Laboratory Glassware, Lauda-Konigshofen, Germany) in a $35 \mathrm{~mm}$ petri dish in the dark. Cells were then incubated in FSW containing $10 \mu \mathrm{mol} \mathrm{L}{ }^{-1} \mathrm{H}_{2}$ DCFDA at room temperature for $1 \mathrm{~h}$ in the dark. Control cells were prepared similarly except that the same volume of DMSO (final concentration $=0.1 \%$ ), rather than $\mathrm{H}_{2} \mathrm{DCFDA}$, was added. Afterwards, cells were washed with FSW twice and then treated with light of either 0 or $80 \mu \mathrm{mol} \mathrm{m} \mathrm{m}^{-2} \mathrm{~s}^{-1}$ for $0-12 \mathrm{~h}$ at $25^{\circ} \mathrm{C}$. The cellular ROS concentration was measured by analyzing the cellular fluorescence intensity of DCF using quantitative microscopy. Briefly, DCF staining of the cell monolayer was recorded sequentially by an Axiovert 200 fluorescence microscope (Carl Zeiss, Oberkochen, Germany) through a CCD camera (CoolSNAP-Procf, Photometrics Ltd., Tucson, AR, USA), first with the band-pass FITC filter (excitation at $480 / 30 \mathrm{~nm}$ and emission at BP $515-565 \mathrm{~nm}$ ) followed by the long-pass FITC filter (excitation at $480 / 30 \mathrm{~nm}$ and emission at LP $515 \mathrm{~nm}$ ). The band-pass filter collected oxidized DCF fluorescence, while the long-pass filter collected fluorescence of both DCF and 
Symbiodinium chlorophyll in the SGC. As a consequence, the fluorescent intensity (gray level/pixel area) of oxidized DCF, representing the cellular ROS levels, was then quantified using the long-pass FITC image as a mask with quantitative imaging processing software (Metamorph Image Processing System; Molecular Devices, Downingtown, PA, USA) as previously described [15,18]. This procedure was repeated on images collected from four to five different cell populations in the same irradiation treatment.

\subsection{Dual-function microscopy for fluorescence and single-cell photosynthesis}

A dual-function microscope was constructed by connecting a pulse amplitude modulation (PAM) chlorophyll fluorescence microfluorometer (Heinz Walz GmbH Effeltrich, Germany [22]) to the Axiovert 200 fluorescence microscope. A beam splitter was used to select the optimal light source, either a mercury lamp for fluorescence imaging or a single blue LED (470 nm) that emitted pulsed, actinic, and saturated light for PAM measurements. For PAM acquisition, a photomultiplier served as the fluorescence detector, and it was operated in conjunction with PC and WinControl software (Walz). For fluorescence image acquisition, microscopy was performed using the same microscope equipped with a Plan-Neofluar (1.3 N.A.) objective and epifluorescence optics for fluorophores such as DAPI, fluorescein, and cy3. The Metamorph Image Processing System (Molecular Devices) was used to control data acquisition through the CCD camera using suitable exposures. Thirty-two fluorescence video images of cells were digitized (16 bits) and averaged.

Aliquots of SGCs and free-living Symbiodinium cells from culture were collected and pretreated in the dark for 2 $\mathrm{h}$ prior to light stimulation $\left(0-80 \mu \mathrm{mol} \mathrm{m} \mathrm{m}^{-2} \mathrm{~s}^{-1}\right)$ prior to being plated onto cover slides for PAM microfluorimetry. In brief, the fluorescence measured by PAM microscopy was excited in a portion of the cells collected. Cells were again dark-adapted for $20 \mathrm{~min}$ at room temperature and their maximal photochemical efficiency (i.e., the maximum quantum yield of PSII), $F_{\mathrm{v}} / F_{\mathrm{m}}$, was measured according to a reported procedure [22].

\subsection{Transmission electron microscopy}

To investigate the ultrastructure of both SGCs and cells from clade C1 Symbiodinium cultures, cells were fixed in $2.5 \%$ glutaraldehyde $/ 2 \%$ formaldehyde with $100 \mathrm{mmol} \mathrm{L}^{-1}$ sodium phosphate $(\mathrm{pH} 7.3)$ for $2.5 \mathrm{~h}$ at $4^{\circ} \mathrm{C}$ and then washed with $100 \mathrm{mmol} \mathrm{L}{ }^{-1}$ sodium phosphate at $4^{\circ} \mathrm{C}$. The tissue was post-fixed in $1 \% \mathrm{OsO}_{4}$ in $50 \mathrm{mmol} \mathrm{L}^{-1}$ sodium phosphate ( $\mathrm{pH} 7.3)$. The tissue blocks were washed with water, dehydrated with increasing concentrations of ethanol $(50 \%, 70 \%, 80 \%, 90 \%, 95 \%, 100 \%)$, and embedded in Spurr's resin. Sections were then post-stained in 5\% uranyl acetate in methanol with lead citrate, deposited onto copper girds, and air-dried. Samples were imaged using a JEM1400 transmission electron microscope (JEOL, Tokyo, Japan).

\subsection{Modulation of plasma membrane cholesterol of SGCs and cultured Symbiodinium}

To deplete or replenish the plasma membrane cholesterol, SGCs or cultured Symbiodinium were incubated with FSW containing $2 \mathrm{mmol} \mathrm{\textrm {L } ^ { - 1 }}$ methyl- $\beta$-cyclodextrin $(\mathrm{M} \beta \mathrm{CD}$; Sigma-Aldrich) or $2 \mathrm{mmol} \mathrm{L}^{-1}$ cholesterol: $\mathrm{M} \beta \mathrm{CD}$ complex (Sigma-Aldrich), respectively, at room temperature for 20 min. To examine the ability of $\mathrm{M} \beta \mathrm{CD}$ to deplete plasma membrane cholesterol, cellular lipids of treated SGCs or cultured Symbiodinium ( $10^{6}$ cells) were first extracted by the Bligh and Dyer procedure [23]. They were then examined using high performance thin layer chromatography (10 $\mathrm{cm} \times 10 \mathrm{~cm}$ silica gel $60 \mathrm{~F}_{254}$ HPTLC plates; E. Merck, Whitehouse Station, NJ, USA) with $\mathrm{CH}_{3} \mathrm{Cl} / \mathrm{CH}_{3} \mathrm{OH} / \mathrm{H}_{2} \mathrm{O}$ $(65: 25: 4, \mathrm{v} / \mathrm{v} / \mathrm{v})$ as the solvent system for chromatographic development. Lipid standards were purchased from either Avanti ${ }^{\circledR}$ Polar Lipids, Inc. (Alabaster, AL, USA) or Sigma-Aldrich. The lipid visualization on HPTLC was performed by either $\mathrm{I}_{2}$ vapor or primuline fluorescence detection [24]. Intensities and the retention factor $\left(R_{\mathrm{f}}\right)$ of lipid spots were determined using the Metamorph Image Processing system (Molecular Devices).

\subsection{Preparation of the BODIPY-SM/DF-BSA complex and cell labeling}

Complexes of BODIPY-SM with DF-BSA were prepared as described previously [25], except with FSW as the solvent $\left(2 \mu \mathrm{mol} \mathrm{L} \mathrm{L}^{-1}\right)$. For labeling with BODIPY-SM/DF-BSA, isolated SGCs $\left(\sim 10^{6}\right.$ cells) were incubated with $2 \mu \mathrm{mol} \mathrm{L}{ }^{-1}$ BODIPY-SM/DF-BSA solution for 30-120 min at room temperature in the dark. Afterwards, cells were gently washed with FSW five times to remove any background staining. The labeling and cellular uptake of BODIPY-lipids was then examined by quantitative fluorescence microscopy and lipid analysis, respectively. To quantify the intensity of BODIPY-SM membrane staining, corrected images of cells were acquired by subtracting background fluorescence using dual-function microscopy, as described above. A mask was then defined by the presence of cell fluorescence, and the average intensity (gray level/pixel) of the cellular fluorescence was calculated as described previously [18]. This procedure was repeated on images collected from 7-10 different cell populations.

Cellular lipids were extracted using the Bligh and Dyer procedure [23]. The total lipid levels were normalized to the number of cells used in the extraction. Two-dimensional high performance liquid chromatography (2D HPTLC) was 
then performed. Chromatographs were developed using the 1st dimensional solvent $\mathrm{CH}_{3} \mathrm{Cl} / \mathrm{CH}_{3} \mathrm{OH} / 28 \% \mathrm{NH}_{4} \mathrm{OH} / \mathrm{H}_{2} \mathrm{O}$ $(72: 48: 2: 9, \mathrm{v} / \mathrm{v})$ and the 2nd dimensional solvent $\mathrm{Et}_{2} \mathrm{O} /$ $\mathrm{Me}_{2} \mathrm{CO}(7: 3, \mathrm{v} / \mathrm{v})$. The BODIPY-lipid contents on HPTLC plates were imaged and analyzed using a Typhoon ${ }^{\mathrm{TM}}$ Trio Imager (Amersham Biosciences, Piscataway, NJ, USA). The resulting lipid content data were expressed as average fluorescence (gray level per pixel) per cell and presented as mean \pm SD.

\subsection{Statistical analysis}

To determine the significance of experimental treatments, paired student's $t$ tests were conducted with SigmaPlot (2004; Systat software, Inc., San Jose, CA, USA). Results were deemed statistically significant if $P<0.05\left(^{*}\right)$ or $P<0.01$ (**).

\section{Results}

\subsection{Identification of gastrodermal plasma membrane in symbiotic gastroderm cells}

Coral-dinoflagellate endosymbiotic associations are characterized by Symbiodinium sp. residing inside gastrodermal cells of diploblastic cnidarian hosts. To focus on these specific cells, the current study prepared large quantities of homogeneous "symbiotic gastrodermal cells" (SGCs). The process of isolating SGCs followed a previous report that performed cell dissociation from inside-out tentacles of $E$. glabrescens [15]. Figure 1 shows differences in membrane structures between SGCs (Figure 1A-D) and cultured Symbiodinium (i.e., free-living clade $\mathrm{C} 1$ Symbiodinium; Figure $\left.1 \mathrm{~A}^{\prime}-\mathrm{D}^{\prime}\right)$. Isolated SGCs contain single to multiple numbers of clade C1 Symbiodinium. Plasma membranes of SGCs can be identified by either differential interference contrast microscopy or fluorescent staining using the sphingomyelin lipid analogue, the BODIPY-SM/DF-BSA complex. A variety of studies have used BODIPY-SM to investigate membrane trafficking in mammalian cells (see [26] for review).

Incubation of SGCs with the BODIPY-SM/DF-BSA complex solution enables incorporation of the BODIPY-SM into the outer leaflet of the SGC plasma membrane [15]. Breakage or permeability changes in the plasma membrane will result in the diffusion of this lipid analogue into the cytosol. As a consequence, this study used BODIPY-SM/ DF-BSA not only to label the plasma membranes of SGCs, but also to examine intactness of gastrodermal plasma membranes in the SGC preparation process [15]. Incubation of SGCs with a $2 \mu \mathrm{mol} \mathrm{L}{ }^{-1}$ BODIPY-SM/DF-BSA complex for $60 \mathrm{~min}$ resulted in integration of the fluorescent lipid into the outer leaflet of the SGC plasma membrane (Figure $1 \mathrm{~A}$ and $\mathrm{B}, \mathrm{PM}_{\mathrm{SGC}}$ indicated by white arrows), as well as the Golgi apparatus (see "G") by metabolites of the BODIPYSM. The fluorescence distribution labeled by "SB" (Figure
$1 \mathrm{~A}$ and $\mathrm{B})$ resulted from the autofluorescence of the storage body (SB) in the symbiont, not from the fluorescent lipids.

The detailed membrane structure of SGCs was also identified by TEM and is schematically demonstrated in Figure $1 \mathrm{C}$ and D. However, the gastrodermal plasma membrane (i.e., $\mathrm{PM}_{\mathrm{SGC}}$ ) was absent in cultured Symbiodinium (Figure $1 \mathrm{~A}^{\prime}$ and $\mathrm{B}^{\prime}$ ) given that these cells were free-living and not housed within coral gastrodermal cells. In cultured Symbiodinium, the cell wall $\left(\mathrm{CW}_{\mathrm{ZX}}\right)$ and other outer membrane layers $\left(\mathrm{OL}_{\mathrm{ZX}}\right)$ represented the outermost boundary (Figure $1 \mathrm{C}^{\prime}$ and $\mathrm{D}^{\prime}$ ), and collectively they prohibited the penetration of BODIPY-SM/DF-BSA complexes (Figure 1A' and B'; see [15] for detail). Based on this result, the purity of SGCs with intact gastrodermal plasma membranes could be quantified by the presence of cell surface BODIPY-SM staining, which was found to occur in at least $\sim 95 \%$ of all isolated SGCs.

\subsection{Effects of light irradiation on the photosynthesis of cultured Symbiodinium and symbiotic gastroderm cells (SGCs)}

Comparisons investigating the effects of light on Symbiodinium photosynthesis in culture and in SGCs should provide critical information regarding how photosynthesis is regulated in endosymbiosis. To address this notion, the maximal photochemical efficiency $\left(F_{\mathrm{v}} / F_{\mathrm{m}}\right)$ of single, cultured Symbiodinium cells and individual SGCs was directly measured using PAM microscopy. Figure 2 shows different photochemical efficiencies between Symbiodinium in culture and in hospite (within SGCs) upon light stimulation. Sustained incubation at $80 \mu \mathrm{mol} \mathrm{m} \mathrm{m}^{-2}$ did not significantly alter $F_{\mathrm{v}} / F_{\mathrm{m}}$ in cultured Symbiodinium compared with those undergoing dark treatment (Figure 2A). On the other hand, light irradiation significantly attenuated the maximal photochemical efficiency of SGCs, resulting in a dramatic decrease in $F_{\mathrm{v}} / F_{\mathrm{m}}$ over time (Figure $2 \mathrm{~B}$ ). Within $3 \mathrm{~h}$ of light irradiation, photochemical efficiency dramatically decreased to $\sim 50 \%$ of the original $\left(F_{\mathrm{v}} / F_{\mathrm{m}}\right.$ decreased from $\sim 0.5$ to $\sim 0.25$ ) and diminished almost to zero after $12 \mathrm{~h}$ of light treatment $\left(F_{\mathrm{v}} / F_{\mathrm{m}} \sim 0.05\right)$. Photosynthesis in SGCs only recovered to $\sim 50 \%$ of the original $F_{\mathrm{v}} / F_{\mathrm{m}}$ after dark treatment for $4 \mathrm{~d}$. Longer culture of these irradiation-treated SGCs was not successful (data not shown).

\subsection{Effects of light irradiation on membrane perturba- tion and cellular oxidative activity}

The significant difference in photochemical efficiencies under light irradiation between the cultured Symbiodinium and SGCs first led to the speculation that structural differences may be the primary cause for this differential response. As Figure 1 shows (see Figure 1D-D'), extraSymbiodinium moieties of the SGC, especially the gastrodermal plasma membrane fraction, represent the major 

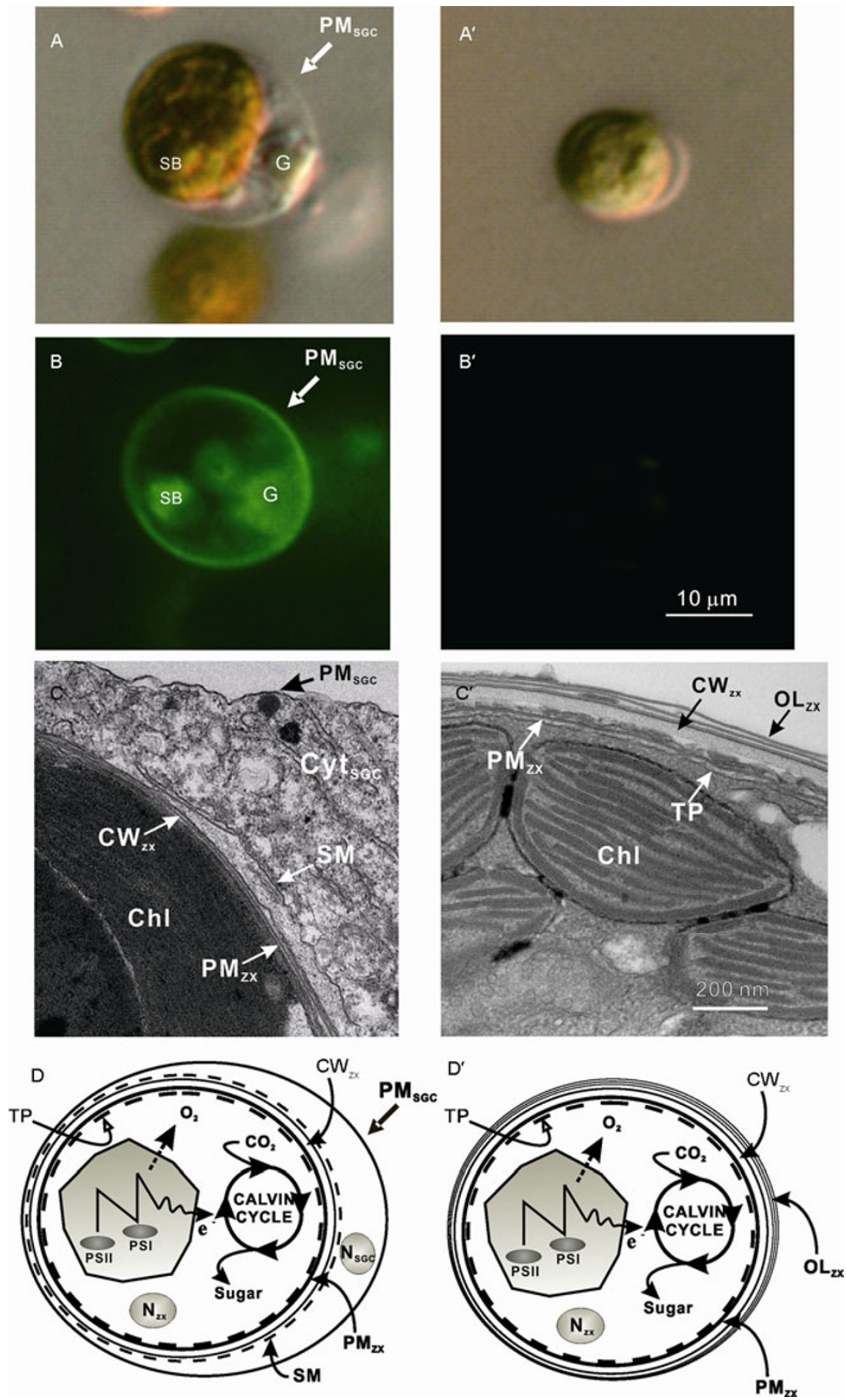

Figure 1 Comparison of plasma membranes between cultured Symbiodinium sp. and isolated symbiotic gastroderm cells. The plasma membranes of isolated symbiotic gastroderm cells (SGCs; A-D) and cultured Symbiodinium sp. (A'-D') are demonstrated by DIC microscopy (A and A'), fluorescent images (B and $\left.\mathrm{B}^{\prime}\right)$, TEM (C and $\mathrm{C}^{\prime}$ ) and schematic illustrations (D and $\left.\mathrm{D}^{\prime}\right)$. Cultured Symbiodinium sp. (clade $\mathrm{C1}$; $\mathrm{C}^{\prime}$ and $\mathrm{D}^{\prime}$ ) display a thecal plate (TP) internal to the plasma membrane $\left(\mathrm{PM}_{\mathrm{ZX}}\right)$, cell wall $\left(\mathrm{CW}_{\mathrm{ZX}}\right)$, and multiple outer membrane layers $\left(\mathrm{OL}_{\mathrm{ZX}}\right)$. The multi-layered outer membranes are not discernible in isolated SGCs and are, instead, replaced by the symbiosome membrane (SM; C and D). The plasma membrane (PM $\mathrm{SGC}_{\mathrm{SC}}$ of the SGC is clearly identified by TEM (C), and by BODIPY-SM/DF- BSA staining as indicated by the thick arrow in B. No plasma membrane can be identified by BODIPY-SM/DF-BSA staining in the cultured Symbiodinium sp. (B'). Other abbreviations: SB, storage body; G, Golgi apparatus; Chl, chloroplasts; $\mathrm{N}_{\mathrm{ZX}}$, nucleus of cultured Symbiodinium; $\mathrm{N}_{\mathrm{SGC}}$, nucleus of SGC; PSI and PSII, photosystems I and II.

structural difference between SGCs and cultured Symbiodinium. As a consequence, the effect of light on the plasma membrane of SGCs was first examined.
To accomplish this, CFW was used to investigate possible membrane structural changes. CFW cannot penetrate intact cell membranes in live and viable cells [27]. Once the 

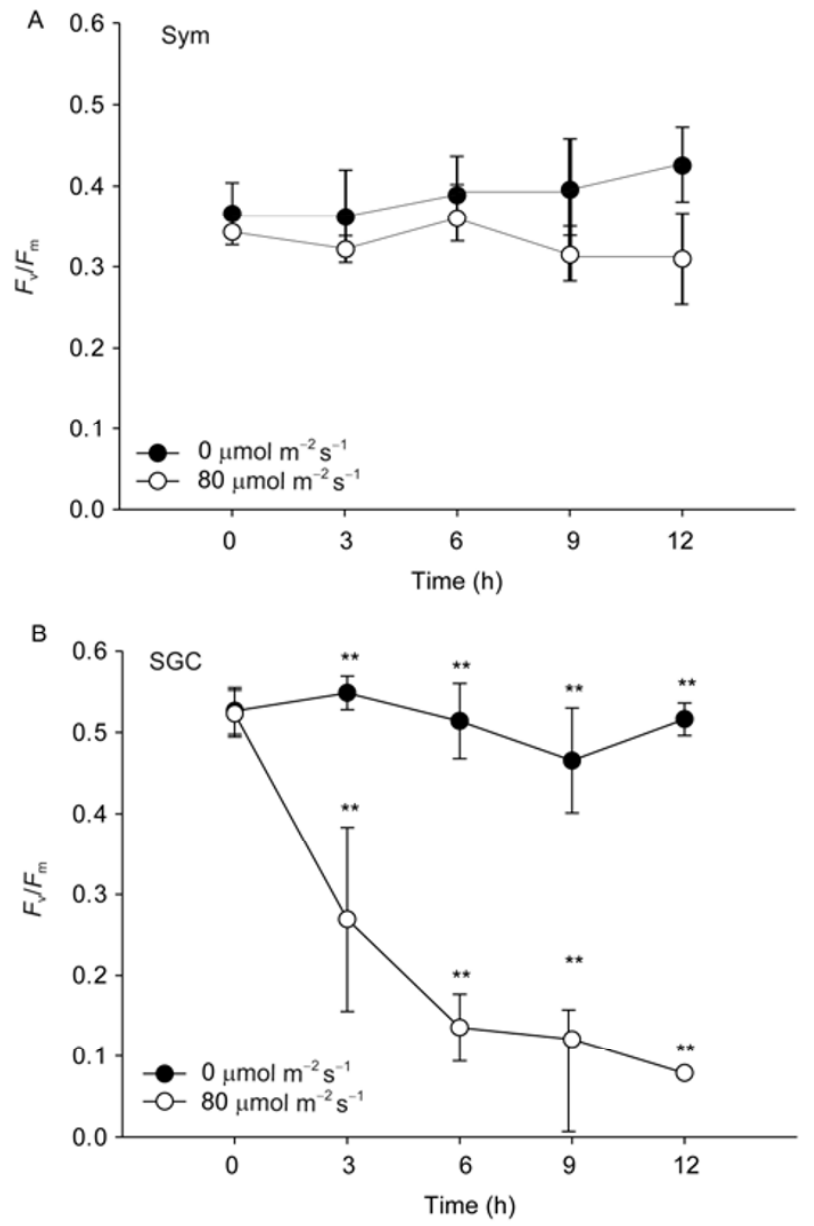

Figure 2 Comparison of irradiation-induced photosynthesis inhibition in cultured Symbiodinium and SGCs. Cultured Symbiodinium (A) and SGCs (B) were subjected to light irradiation at 0 (filled circles) or $80 \mu \mathrm{mol} \mathrm{m} \mathrm{m}^{-2} \mathrm{~s}^{-1}$ (blank circles) for $0-12 \mathrm{~h}$, and measurements were made every $3 \mathrm{~h}$. The values for the maximum quantum yield of photosystem II $\left(F_{\mathrm{v}} / F_{\mathrm{m}}\right)$ were examined by microscopy-PAM. Each data point represents mean \pm SD of five biological replicates. $* *, P<0.01$.

membrane is perturbed, $\mathrm{CFW}$ penetrates the membrane and binds with components in the underlying cell wall, such as cellulose, chitin, carboxylated polysaccharides, and a variety of other $\beta$-linked polymers [28]. CFW has also been used to visualize thecal plates of dinoflagellates $[29,30]$. Because of the fact that Symbiodinium sp. contains a cell covering, or amphiesma, of a typical thecate cell wall (i.e., internal cell wall; [30]), only fixed, permeabilized cells or cells with altered membranes will allow $\mathrm{CFW}$ to penetrate the outer plasma membranes and bind to the cellulose of the internal cell walls. Figure $3 \mathrm{~A}$ shows that increasing the duration of light irradiation at $80 \mu \mathrm{mol} \mathrm{m} \mathrm{m}^{-2} \mathrm{~s}^{-1}$ significantly perturbed plasma membranes in SGCs indicated by increased CFW staining on the cell wall, but that cultured Symbiodinium remained intact. During the first $3 \mathrm{~h}$ of light irradiation, no significant CFW staining was observed in SGCs. Significant increases in CFW staining of cell walls only occurred $6 \mathrm{~h}$
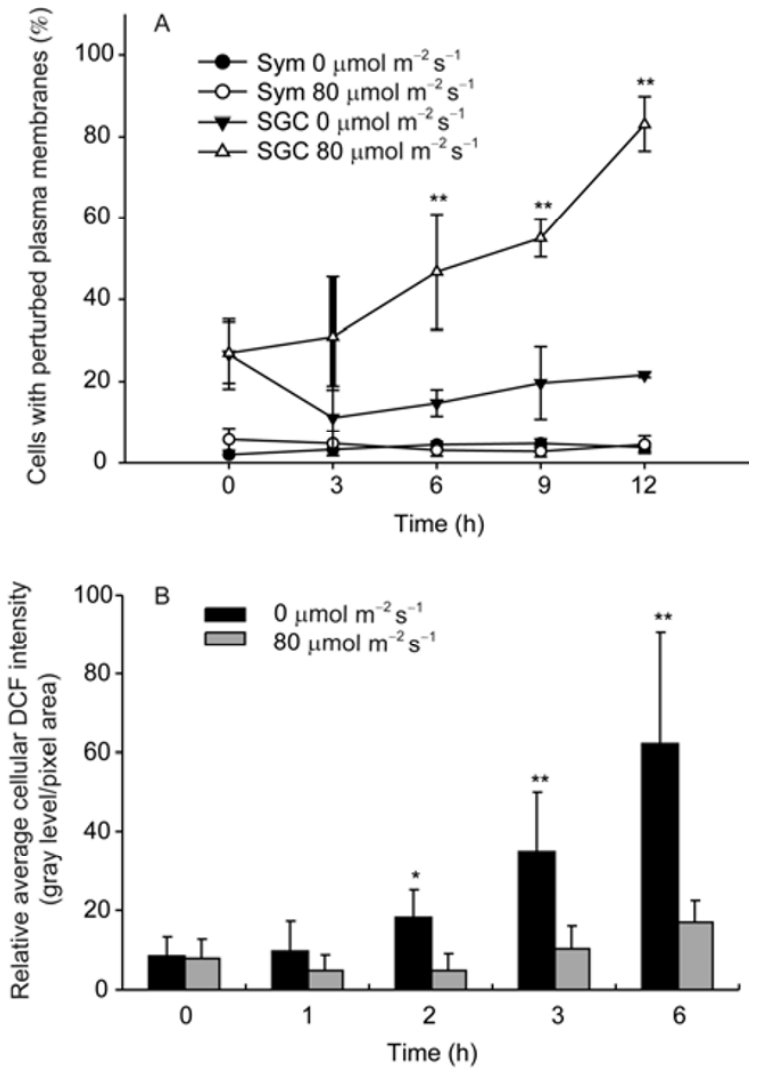

Figure 3 Effect of light irradiation on membrane perturbation and cellular ROS concentration. A, Cultured Symbiodinium (Sym) and isolated SGCs were subjected to light irradiation at 0 or $80 \mu \mathrm{mol} \mathrm{m}^{-2} \mathrm{~s}^{-1}$ for $0-12 \mathrm{~h}$, and sampling was conducted every $3 \mathrm{~h}$. Plasma membrane perturbation induced by light irradiation was examined by CFW staining. B, SGCs were subjected to the same light irradiation for $0-6 \mathrm{~h}$, and the cellular ROS concentrations were examined using the probe $\mathrm{H}_{2}$ DCFDA. Data were averaged from five repetitions and are expressed as mean $\pm \mathrm{SD}$.

$$
\text { *, } P<0.05 \text {; **, } P<0.01 \text {. }
$$

after light irradiation but remained significantly low in the dark for SGCs. Nevertheless, the membranes of cultured Symbiodinium were not perturbed by light irradiation throughout the experiment.

The experiment further monitored changes to the cellular redox status during the first $3 \mathrm{~h}$ of light irradiation when there was no significant CFW staining by directly measuring SGC oxidative activity using $\mathrm{H}_{2}$ DCFDA (Figure $3 \mathrm{~B}$ ). Under dark treatment (i.e., $0 \mu \mathrm{mol} \mathrm{m} \mathrm{m}^{-2}$ ), there was no significant difference in the ROS production during the first $3 \mathrm{~h}$ as shown by the relative average cellular fluorescence of oxidized DCF (Figure 3B). On the contrary, there was a gradual increase in ROS production starting at $2 \mathrm{~h}$ after light irradiation ((18.3 \pm 7.0) gray level/pixel area), which then increased significantly after $3 \mathrm{~h}$ of irradiation $((35.0 \pm 15.0)$ gray level/pixel area). Cellular ROS kept increasing to a $(62.0 \pm 28.7)$ gray level/pixel area in intact cells after $6 \mathrm{~h}$ of irradiation. This strongly indicates that there was an irradiation-induced increase in ROS generation in SGCs during the first $3 \mathrm{~h}$ of light-irradiation before membrane permeability changed. 


\subsection{Effect of SGC plasma membrane cholesterol on symbiont photochemical efficiency}

The photosynthetic apparatuses of SGCs and cultured Symbiodinium are presumably structurally identical (Figure 1D and $\mathrm{D}^{\prime}$ ) given that both are from Symbiodinium of clade C1. The major differences in the cellular structure between SGCs and cultured Symbiodinium is the presence of the host gastrodermal cell, as well as the plasma $\left(\mathrm{PM}_{\mathrm{SGC}}\right)$ and symbiosome membranes (SM) surrounding the symbiotic Symbiodinium. To examine whether there is interaction between the gastrodermal plasma membrane and Symbiodinium photosynthesis in SGCs, the gastrodermal plasma membrane fluidity was altered by specifically removing plasma membrane cholesterol using methyl- $\beta$-cyclodextrin $(\mathrm{M} \beta \mathrm{CD})$ and then examined to determine whether photosynthesis was affected in these cholesterol-depleted SGCs. Cholesterol is abundant in cnidarian species, including sea anemones and various corals [31,32]. The ability of M $B C D$ to remove plasma membrane cholesterol was first assessed by lipid analysis using thin-layer chromatography in both SGCs and cultured Symbiodinium (Figure 4). After the 2 mmol L ${ }^{-1} \mathrm{M} \beta C D$ treatment, $~ 100 \%$ of plasma membrane cholesterol was removed from SGCs as shown by HPTLC analysis (arrows in Figure 4A). Interestingly, cholesterol was not detected in cultured Symbiodinium (arrow in Figure $4 \mathrm{~B}$, left panel), and $\mathrm{M} \beta \mathrm{CD}$ treatment did not alter the lipid composition pattern on HPTLC. Furthermore, Symbiodinium pigments were not affected by the $\mathrm{M} \beta \mathrm{CD}$ treatment (Figure 4B, right panel).

Figure 3A shows that irradiation treatment at $80 \mu \mathrm{mol}$ $\mathrm{m}^{-2} \mathrm{~s}^{-1}$ for longer than $3 \mathrm{~h}$ resulted in membrane permeability changes in SGCs. Effects of cholesterol depletion on Symbiodinium photosynthesis in culture and in hospite (in SGCs) were then measured with $0-80 \mu \mathrm{mol} \mathrm{m} \mathrm{m}^{-2} \mathrm{~s}^{-1}$ light irradiation at room temperature for $3 \mathrm{~h}$ to ensure good cell viability (Figure 5). Compared with the control treatment (i.e., FSW fractions), cholesterol depletion by $2 \mathrm{mmol} \mathrm{L}^{-1}$ M $\beta C D$ treatment did not affect the photosynthesis of cultured Symbiodinium regardless of light irradiation (Figure $5 \mathrm{~A})$. This result further confirms that acclimation irradiation does not alter photosynthesis of cultured Symbiodinium. However, similar to that shown in Figure 2B during the first $3 \mathrm{~h}$, light irradiation decreases the maximal photochemical efficiency of SGCs in a dose-dependent manner, with $F_{\mathrm{v}} / F_{\mathrm{m}}$ decreasing from $\sim 0.5$ to $\sim 0.3$ after $80 \mu \mathrm{mol} \mathrm{m}^{-2} \mathrm{~s}^{-1}$ treatment (Figure 5B, FSW fractions). Furthermore, M $\beta C D$ treatment (Figure 5B, M $\beta C D$ treatment fractions) further augments light-induced photo-inhibition, with $F_{\mathrm{v}} / F_{\mathrm{m}}$ decreasing from $\sim 0.5$ to $\sim 0.1$. The cholesterol-depleting effect on SGC photosynthesis is specific, because replenishing cholesterol to the plasma membrane by treating SGCs with cholesterol (i.e., water-soluble cholesterol, molar ratio 1:6 cholesterol/M $\beta \mathrm{CD}$ ) did not exacerbate light-dependent
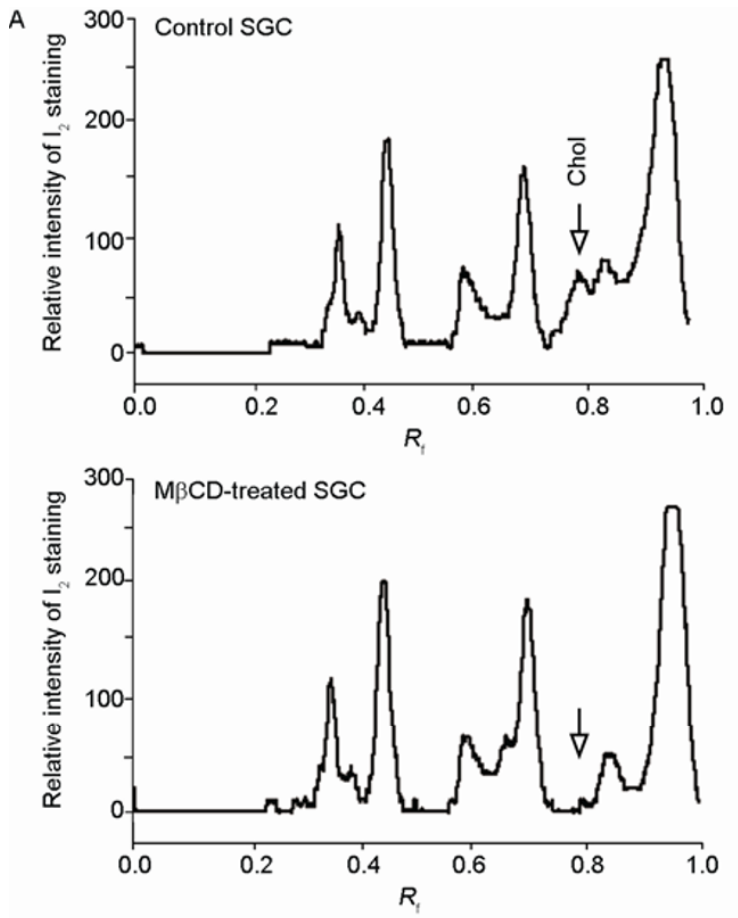

B

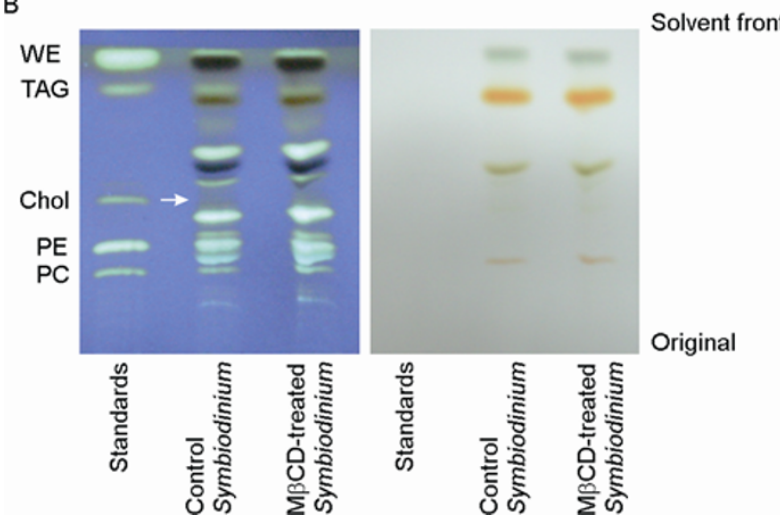

Figure 4 HPTLC examination of the effects of M $\beta C D$ on cholesterol levels in SGCs and cultured Symbiodinium. SGCs $\left(10^{6}\right.$ cells; A) or cultured Symbiodinium $\left(10^{6}\right.$ cells; B) were treated with or without $2 \mathrm{mmol} \mathrm{L}^{-1}$ $\mathrm{M} \beta \mathrm{CD}$ in FSW at room temperature for $20 \mathrm{~min}$. Cellular lipids were extracted and examined by HPTLC (solvent system: $\mathrm{CH}_{3} \mathrm{Cl} / \mathrm{CH}_{3} \mathrm{OH} / \mathrm{H}_{2} \mathrm{O}$ $(65: 25: 4, v / v / v)$. A, The comparison of lipid spot intensities after $I_{2}$ vapor exposure vs. $R_{\mathrm{f}}$ values between the control and M $\beta C D$-treated SGCs. As indicated by arrows, cholesterol (with $R_{\mathrm{f}} 0.79$ ) in SGCs was completely depleted after $\mathrm{M} \beta \mathrm{CD}$ treatment. B, The lipid content in cultured Symbiodinium treated with or without $\mathrm{M} \beta \mathrm{CD}$ was compared by HPTLC with perimuline staining. The left panel is the plate fluorescence image to show the lipid contents, and the right panel is the bright light image of the same plate to show the pigments. The arrow on the left panel indicates the absence of cholesterol in both control and M $\beta C D$-treated cultured Symbiodinium. Abbreviations of standard lipid standards: WE, wax ester; TAG, triacylglycerol; Chol, cholesterol; PE, phosphatidylethanoamine; PC, phosphatidylcholine.

photo-inhibition (Figure 5C).

\subsection{Effect of light irradiation and cholesterol depletion on membrane metabolism in SGCs}

Membrane trafficking in SGCs was monitored by examin- 

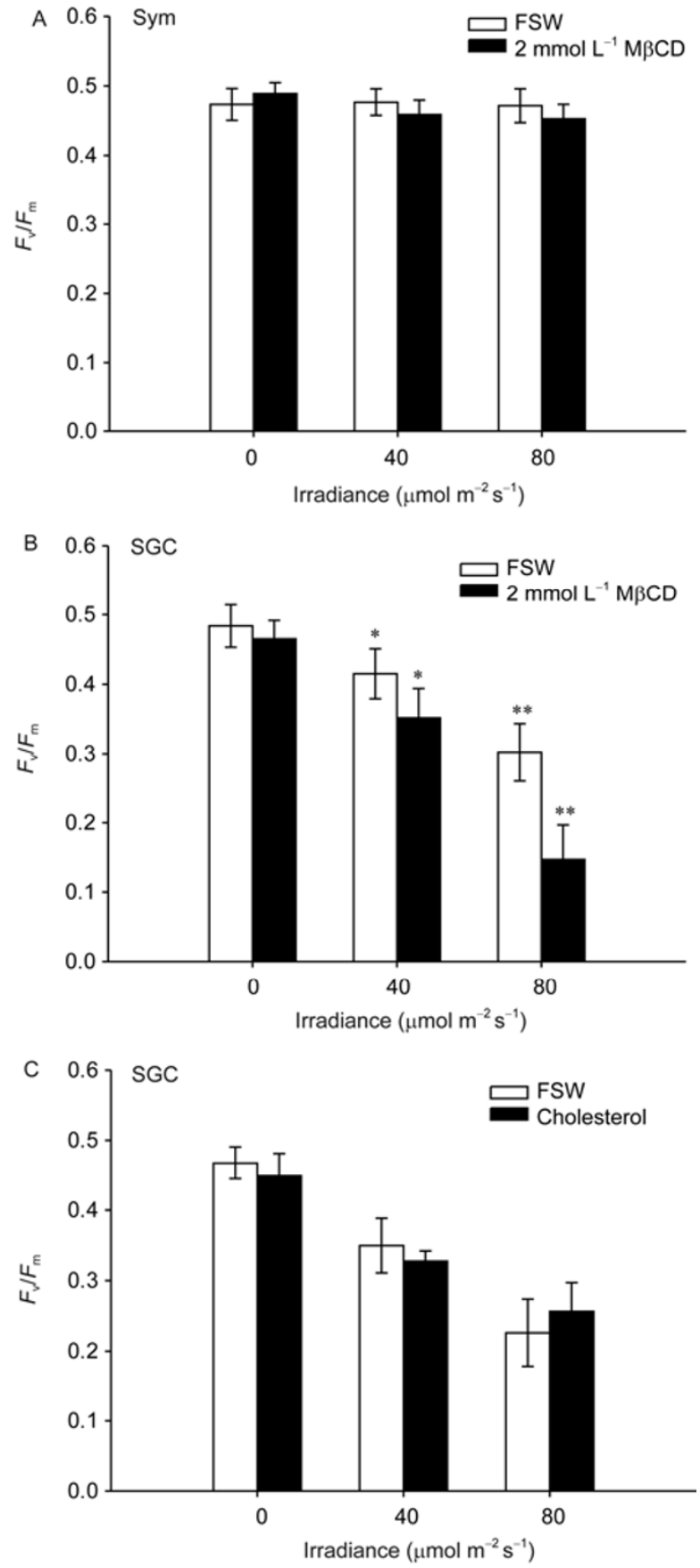

Figure 5 Differential effects of plasma membrane cholesterol on photo-inhibition of cultured Symbiodinium and SGCs. Cells (A, Symbiodinium sp.; B, SGC) were treated with or without $2 \mathrm{mmol} \mathrm{L}^{-1} \mathrm{M} \beta \mathrm{CD}$, or with 2 mmol L ${ }^{-1}$ cholesterol: $\mathrm{M} \beta C D$ complex (SGC only; $\mathrm{C}$ ) at room temperature for $20 \mathrm{~min}$, followed by increasing doses of irradiation $\left(0-80 \mu \mathrm{mol} \mathrm{m}^{-2} \mathrm{~s}^{-1}\right)$ at room temperature for $3 \mathrm{~h} . F_{\mathrm{v}} / F_{\mathrm{m}}$ was measured and averaged from seven repetitions in each treatment. *, $P<0.05$; **, $P<0.01$.

ing BODIPY-SM degradation. In the endocytic pathway, BODIPY-SM is either recycled back to the plasma membrane or transported into lysosomes and degraded into BODIPY-Ceramide (Cer) by lysosomal Sphingomyelinase (SMase), as reported in various mammalian cells during endocytic pathways [33]. As a consequence, the metabolism of BODIPY-SM, which reflects trafficking inside cells, was examined in SGCs. First, the feasibility of BODIPY-SM as a fluorescent probe for membrane metabolism was tested. During a pulse-chase experiment with $2 \mu \mathrm{mol} \mathrm{L}^{-1}$ of BODIPY-SM/DF-BSA complex in SGCs in the dark, cellular lipids were extracted and analyzed by two-dimensional high performance thin-layer chromatography (2D-HPTLC). Figure 6 shows cellular degradation of BODIPY-SM in SGCs. The degradation product, BODIPY-Cer, was identified $0.5 \mathrm{~h}$ after pulse-labeling with BODIPY-SM/DF-BSA. After $2 \mathrm{~h}$ of incubation, integrated BODIPY-SM was totally degraded into BODIPY-Cer, indicating trafficking from the plasma membrane to the lysosomes.

The effect of light irradiation on BODIPY-SM metabolism was then examined (Table 1). Cells were first treated with or without $\mathrm{M} \beta \mathrm{CD}\left(2 \mathrm{mmol} \mathrm{L}{ }^{-1}\right)$ for $20 \mathrm{~min}$ to deplete the plasma membrane cholesterol, followed by increasing light irradiation treatments $\left(0,40,80 \mu \mathrm{mol} \mathrm{m} \mathrm{s}^{-1}\right)$ for $3 \mathrm{~h}$. Cells were then incubated with a BODIPY-SM/DF-BSA complex $\left(2 \mu \mathrm{mol} \mathrm{L}^{-1}\right)$ at room temperature for $2 \mathrm{~h}$. BODIPY-lipids in $10^{6}$ cells were then analyzed by 2DHPTLC. Table 1 shows that the amount of BODIPY-lipid uptake ("cell-associated BODIPY-lipids") in control cells remained constant (average fluorescence $\sim 6.38-6.85$ per $10^{6}$ cells) under different light irradiation treatments. Furthermore, light irradiation significantly reduced BODIPY-SM degradation into BODIPY-Cer. The ratio of cellular BODIPY-Cer:BODIPY-SM under light treatment decreased

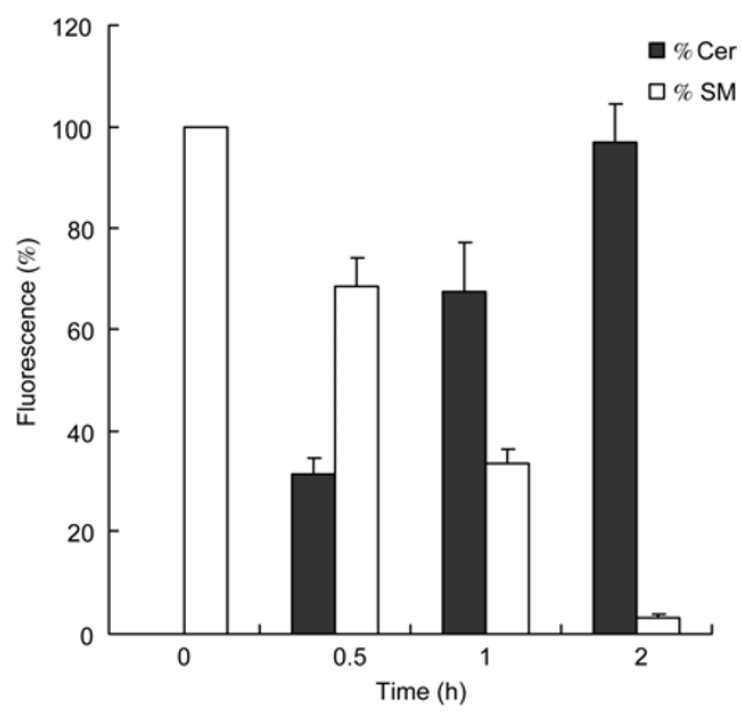

Figure 6 Metabolism of BODIPY-SM in SGCs. BODIPY-SM was used as a probe to investigate trafficking and metabolism of membrane lipids. The cellular metabolism of BODIPY-SM in SGCs was examined in a pulse-chase experiment. SGCs were pulse-labeled with $2 \mu \mathrm{mol} \mathrm{L} \mathrm{L}^{-1}$ BODIPY-SM/DF-BSA at room temperature for $30 \mathrm{~min}$, followed by incubation for $0-2 \mathrm{~h}$. The cellular contents of BODIPY-lipids (i.e., BODIPY-SM and BODIPY-Cer) were extracted and analyzed using two-dimensional high performance thin-layer chromatography. Four replicates were used for each treatment, and the data are expressed as mean \pm SD. 
Table 1 Effects of light irradiation and cholesterol depletion on BODIPY-SM metabolism ${ }^{\text {a) }}$

\begin{tabular}{|c|c|c|c|}
\hline & $\begin{array}{l}\text { Light irradiation } \\
\left(\mu \mathrm{mol} \mathrm{m} \mathrm{m}^{-2}\right)\end{array}$ & $\begin{array}{l}\text { Cell-associated BODIPY-lipids } \\
\text { (average fluorescence } / 10^{6} \text { cells) }\end{array}$ & $\begin{array}{c}\text { Ratio of BODIPY-lipids } \\
\text { (Cer:SM) }\end{array}$ \\
\hline \multicolumn{4}{|l|}{ Control } \\
\hline & 0 & $6.75 \pm 0.07$ & $(29.73 \pm 1.65): 1$ \\
\hline & 40 & $6.85 \pm 0.49$ & $(8.89 \pm 0.52): 1^{*}$ \\
\hline & 80 & $6.38 \pm 0.66$ & $(6.55 \pm 0.31): 1^{*}$ \\
\hline \multicolumn{4}{|l|}{$\mathrm{M} \beta \mathrm{CD}$} \\
\hline & 0 & $7.26 \pm 0.41$ & $(1.18 \pm 0.11): 1$ \\
\hline & 40 & $13.55 \pm 0.35^{*}$ & $(0.55 \pm 0.22): 1^{*}$ \\
\hline & 80 & $14.90 \pm 0.42^{*}$ & $(0.38 \pm 0.03): 1^{*}$ \\
\hline
\end{tabular}

a) SGCs were first treated with or without $2 \mathrm{mmol} \mathrm{L}^{-1} \mathrm{M} \beta C D$ for $20 \mathrm{~min}$, followed by light irradiation $\left(0,40,80 \mu \mathrm{mol} \mathrm{m} \mathrm{s}^{-1}\right)$ for $3 \mathrm{~h}$ at room temperature. Cells were then pulse-labeled with $2 \mu \mathrm{mol} \mathrm{L}{ }^{-1}$ BODIPY-SM/DF-BSA complex for 2 h. Cellular lipids were analyzed with $2 \mathrm{D}-\mathrm{HPTLC}$. Each value represents the mean $\pm \mathrm{SD}$ for triplicates, and is considered significant when $P<0.05$ (*) (Student's $t$ test).

from $\sim 29.73$ to $6.55-8.89$. In the absence of light irradiation $\left(0 \mu \mathrm{mol} \mathrm{m} \mathrm{m}^{-2}\right)$, cholesterol depletion by $\mathrm{M} \beta \mathrm{CD}$ did not significantly affect the BODIPY-lipid uptake, as compared with the control treatment (7.26 \pm 0.41 vs. $6.75 \pm 0.07)$. However, the BODIPY-lipid degradation in M $\beta C D$-treated cells was drastically reduced $(1.18 \pm 0.11$ vs. $29.73 \pm 1.65)$. Surprisingly, light irradiation enhanced lipid uptake and further augmented their degradation reduction: light irradiation treatment at $40-80 \mu \mathrm{mol} \mathrm{m} \mathrm{m}^{-2} \mathrm{~s}^{-1}$ resulted in an approximately 2-fold increase in lipid uptake and a 3-fold decrease in BODIPY-SM degradation compared with dark treatment upon $\mathrm{M} \beta \mathrm{CD}$ incubation.

\section{Discussion}

Symbiodinium sp. reside within cells of the gastrodermal tissue layer of certain cnidarian [34]. The regulation of this mutually beneficial endosymbiosis still remains unclear, even after decades of research [35-37]. Although a variety of mechanisms have been proposed, cellular and molecular verification for most have not been achieved. This delay in progress is mostly due to the inability to obtain homogeneous gastrodermal cells in large quantities [38]. Herein, isolated gastrodermal cell populations were first exploited to gain insight into the role of the host-derived membranes of the SGCs on Symbiodinium photosynthesis. Cultured Symbiodinium of the same genetic clade (clade $\mathrm{C} 1$ ) as those residing within the experimental SGCs were compared. The overall results show that stress susceptibility in SGCs in response to irradiation is higher than that of cultured Symbiodinium (Figure 2). Increasing light irradiation decreases the maximal photochemical efficiency of SGCs but not of cultured Symbiodinium. There were concurrent changes in permeability and metabolism in SGC plasma membranes. Based on these results, this study poses that there is a close interaction between the membrane trafficking of SGCs and Symbiodinium photosynthesis in a light-dependent fashion, as shown in Figure 7.

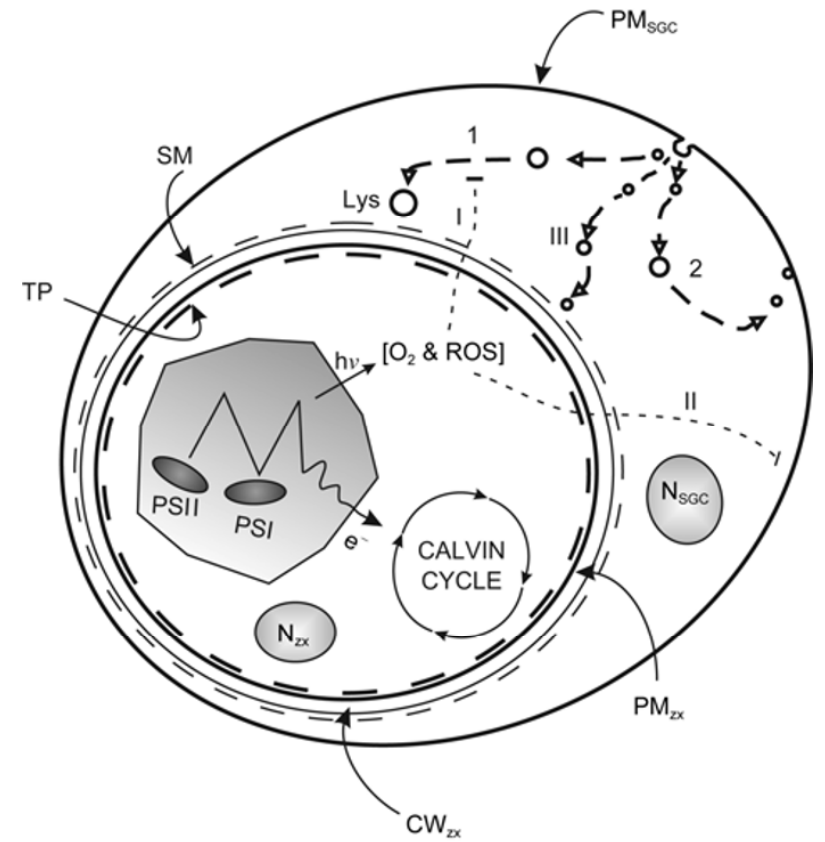

Figure 7 Model of photosynthesis regulation by membrane trafficking in a symbiotic gastrodermal cell under light-irradiation. $\mathrm{PM}_{\mathrm{SGC}}$, plasma membrane of SGC; Lys, lysosome; SM, symbiosome membrane; TP, thecal plate; $\mathrm{N}_{\mathrm{ZX}}$, nucleus of the symbiont; $\mathrm{N}_{\mathrm{SGC}}$, nucleus of SGC; PSI and PSII, photosystems I and II; hv, light irradiation; ROS, reactive oxygen species; $\mathrm{CW}_{\mathrm{ZX}}$, cell wall of the symbiont; $\mathrm{PM}_{\mathrm{Zx}}$, plasma membrane of the symbiont. Pathways I and II indicate possible interactions of $\mathrm{O}_{2} \&$ ROS on lysosomal-targeted trafficking (i.e., pathway 1) and the membrane composition/structure of $\mathrm{PM}_{\mathrm{SGC}}$. Pathways 1, 2 and III represent membrane trafficking from the $\mathrm{PM}_{\mathrm{SGC}}$ to the host lysosome, recycling, and the Symbiodinium, respectively.

\subsection{Endosymbionts' ROS generation during light irra- diation alters SGC plasma membrane trafficking (pathways I and II; Figure 7)}

BODIPY-SM has been used as a marker for endocytosis in mammalian cells [25]. In mammalian cells, most BODIPY$\mathrm{SM}$ has been shown to be recycled back to the plasma membrane after endocytosis, while $\sim 15 \%$ of BODIPY-SM is further transported into lysosomes, where it is degraded 
into BODIPY-Ceramide (BODIPY-Cer) by acidic sphingomyelinase (SMase) [33]. In SGCs, a large amount of BODIPY-Cer $(30 \%-100 \%)$ was generated within $2 \mathrm{~h}$ of pulse-labeling with BODIPY-SM in the absence of light irradiation (Figure 6, Table 1), indicating endocytosis of BODIPY-SM and trafficking to "lysosome-like" compartments where BODIPY-SM is degraded into BODIPY-Cer (i.e., pathway 1 in Figure 7). However, it was found that light irradiation reduced BODIPY-SM degradation (Table 1), which should result from an alteration in membrane trafficking of the host plasma membrane along a lysosome-like pathway. Free-radical species such as ROS are generated during the light reactions of photosynthesis [39]. The use of fluorescent probes indicated that ROS were not produced at substantial levels until $3 \mathrm{~h}$ of light irradiation had occurred, the time at which noticeable membrane perturbation, as evidenced by labeling with Calcofluor White M2R, was observed (Figure 3). The irradiation-induced elevation of ROS activity may oxidize membrane lipids and inhibit lysosomal-like trafficking (pathway I in Figure 7) or plasma membrane composition (pathway II in Figure 7). As a consequence, upon light irradiation, the lysosomal-like trafficking of BODIPY-SM is retarded in a dose-dependent manner, resulting in decreased BODIPY-SM degradation (Table 1).

Cholesterol is abundant in cnidarian species and accounts for $\sim 14 \%$ of the total cellular lipids [40]. The depletion of plasma membrane cholesterol using M $\beta C D$ not only further inhibited light-dependent lipid degradation, but also significantly increased the plasma membrane content of BODIPY-SM (Table 1). Cholesterol depletion may alter membrane fluidity and the structure of membrane domains (e.g., "lipid rafts" or "caveolae"; see [41] and cited references therein), leading to alteration of endocytosis as indicated by further retardation of BODIPY-SM degradation (Table 1). These observations suggest that cholesterol depletion not only blocks lysosomal-like trafficking (pathway 1 in Figure 7) but also accelerates recycling trafficking (pathway 2 in Figure 7) under the light irradiation.

\subsection{Changes in SGC membrane trafficking further inhibits endosymbionts' photosynthetic efficiency (pathway III; Figure 7)}

Endosymbiosis has been reported to be initiated by the phagocytosis of free-living Symbiodinium into gastrodermal cells [2]. Phagosome membranes that enclose the dinoflagellates originate from gastrodermal plasma membranes and eventually develop into symbiosome membranes that resist fusion with lysosomes. Chen et al. [3] have shown that symbiosome membranes actively exclude a late endosome-specific Rab 7 protein analog (ApRab7), which indicates specific membrane sorting in the Symbiodinium-sea anemone association. However, direct evidence showing that membrane trafficking may modulate symbiosis stability is still lacking. Using proteomic analyses, $30 \%$ of the symbiosome membrane-associated proteins have been shown to be derived from the plasma membranes in the gastroderm of the sea anemone Aiptasia pulchella [4].

The present study only identified cholesterol in SGCs, and not in cultured Symbiodinium (Figure 4). Furthermore, M $\beta C D$ cannot penetrate the cell walls of cultured Symbiodinium [42,43] nor affect their photosynthesis (Figure 5A). In fact, it can only deplete cholesterol from the gastrodermal plasma membrane. Intriguingly, the fact that cholesterol depletion of the SGC plasma membrane by M $\beta C D$ treatment only affected the maximal photosynthetic efficiency of residing Symbiodinium in the presence of light irradiation (40-80 $\mu \mathrm{mol} \mathrm{m} \mathrm{m}^{-2} \mathrm{~s}^{-1}$ light irradiation; Figure 5B), strongly suggests that an alteration of host membrane trafficking (or metabolism) induced by ROS generation under light irradiation is critical for photosynthesis modulation.

These data demonstrated the critical role of membrane trafficking between the gastrodermal plasma membranes, symbiosome membranes, and the Symbiodinium in the regulation of endosymbiosis. In other words, modulating gastrodermal plasma membrane integrity or composition, such as with light irradiation or cholesterol depletion, may result in alteration of membrane trafficking and lead to physiological changes in the Symbiodinium (i.e., pathway III; Figure 7).

\subsection{The use of SGCs and implications in situ}

Through inside-out manipulation followed by mechanical dissociation and filtration, large amounts of intact SGCs were collected, and the degree of membrane intactness of these SGCs was demonstrated by labeling with a BODIPYSM/BSA complex [15] on the surface only. It remains to be elucidated by more sophisticated techniques regarding to what degree the membrane lipid distribution and composition may be affected by the SGC isolation process. For example, in situ SGCs are polarized cells with tight junctions connected to neighbor cells [44]. The preparation of isolated SGCs may disrupt the membrane lipid distribution, but likely not their composition. During a week-long incubation in the dark, the viability of these SGCs was maintained at $70 \%-95 \%$, as examined by trypan blue and propidium iodide staining (data not shown); however, long-term culture of these SGCs was not successful.

Nevertheless, the high sensitivity of both $F_{\mathrm{v}} / F_{\mathrm{m}}$ and membrane trafficking to light irradiation in the SGC could provide insight into coral development at the tissue and organismal levels. Although endosymbiosis only occurs in the gastroderm of the adult host polyp, it may also be regulated by the epiderm. For example, the epidermis of E. glabrescens contains significant amounts of green fluorescent proteins [45]. Fluorescent pigments or proteins in corals play a photo-protective or regulatory role for various coral processes, including reproduction [46]. The green fluores- 
cent epidermal layer may screen the incoming light for optimal irradiation intensities or wavelengths to modulate membrane trafficking of the underlying gastrodermal cells, leading to photosynthetic changes in the gastrodermally-localized photosymbionts. Similar interactions may occur in other hermatypic corals, in which colony morphology and size have been reported to be correlated with light harvesting efficiency [47]. Various light harvesting efficiencies in different regions of the coral colony could lead to dynamic membrane trafficking and lipid metabolism of SGCs in situ. This could lead to the documented lipid profile differences measured across branching coral colonies [31].

$\begin{array}{ll}\text { Abbreviations } \\ \text { BODIPY-Cer } & \text { BODIPY-ceramide } \\ \text { BODIPY-SM } & \text { BODIPY-sphingomyelin } \\ \text { CFW } & \text { calcofluor white M2R } \\ \text { DCF } & \text { dichlorofluorescin; } \\ \text { FSW } & \text { filtered seawater; } \\ \text { H}_{2} \text { DCFDA } & 2^{\prime}, 7^{\prime} \text {-dichlorodihydrofluorescein diacetate } \\ \text { HPTLC } & \text { high performance thin layer chromatography } \\ \text { M } \beta C D & \text { methyl- } \beta \text {-cyclodextrin } \\ \text { PAM } & \text { pulse amplitude modulation } \\ \text { ROS } & \text { reactive oxygen species } \\ \text { SGC } & \text { symbiotic gastrodermal cell } \\ \text { Sym } & \text { Symbiodinium }\end{array}$

The present study is dedicated to the memory of our mentor Professor Richard E. Pagano (1944-2010), a distinguished lipid cell biologist. This work was supported by the National Science Council of Taiwan (Grant No. NSC 98-2311-B-291-001-MY3). We would like to acknowledge Dr. Anderson Mayfield for his assistance in the English proofing of the manuscript.

1 Rowan R. Thermal adaptation in reef coral symbionts. Science, 2004, 430: 742

2 Hohman T C, McNeil P L, Muscatine L. Phagosome-lysosome fusion inhibited by algal symbionts of Hydra viridis. J Cell Biol, 1982, 94: 56-63

3 Chen M C, Cheng Y M, Sung P J, et al. Molecular identification of Rab7 (ApRab7) in Aiptasia pulchella and its exclusion from phagosomes harboring Symbiodinium. Biochem Biophys Res Comm, 2003, 308: 586-595

4 Peng S E, Wang Y B, Wang L H, et al. Proteomic analysis of symbiosome membranes in cnidaria-dinoflagellate endosymbiosis. Proteomics, 2010, 10: 1002-1016

5 Muscatine L. The role of symbiotic algae in carbon and energy flux in reef corals. In: Dubinsky Z, ed. Coral Reefs Ecosystems of the World. Amsterdam: Elsvier, 1990. 75-87

6 Saxby T, Dennison W C, Hoegh-Guldberg O. Photosynthetic responses of the coral Montipora digitata to cold temperature stress. Mar Ecol Progress Ser, 2003, 248: 85-97

7 Lesser M P, Farrell J H. Exposure to solar radiation increases damage to both host tissues and algal symbionts of corals during thermal stress. Coral Reefs, 2004, 23: 367-377

8 Takshashi S, Nakamura T, Sakamizu M, et al. Repair machinery of symbiotic photosynthesis as the primary target of heat stress for reef-building corals. Plant Cell Physiol, 2004, 45: 251-255

9 Bhagooli R, Hidaka M. Comparison of stress susceptibility of in hospite and isolated Symbiodinium among five coral species. J Exp Mar Biol Ecol, 2003, 291: 181-197
10 Baruch R, Avishai N, Rabinowitz C. UV incites diverse levels of DNA breaks in different cellular compartments of a branching coral species. J Exp Biol, 2005, 208: 843-848

11 Lesser M P, Shick J M. Effects of irradiance and ultraviolet radiation on photoadaptation in the Symbiodinium of Aiptasia pallida: primary production, photo-inhibition, and enzymatic defenses against oxygen toxicity. Mar Biol, 1989, 102: 243-255

12 Lesser M P. Exposure of symbiotic dinoflagellates to elevated temperatures and ultraviolet radiation causes oxidative stress and inhibits photosynthesis. Limnol Oceanogr, 1996, 41: 271-283

13 Lesser M P. Oxidative stress causes coral bleaching during exposure to elevated temperatures. Coral Reefs, 1997, 16: 187-192

14 Tchernov D, Gorbunov M Y, de Vargas C, et al. Membrane lipids of symbiotic algae are diagnostic of sensitivity to thermal bleaching in corals. Proc Natl Acad Sci USA, 2004, 101: 13531-13535

15 Chen C S, Lin H P, Yeh C C, et al. Use of a fluorescent membrane probe to identify Symbiodinium in hospite among dissociated gastroderm cell culture from coral. Protoplasma, 2005, 226: 175-179

16 Wang L H, Liu Y H, Ju Y, et al. Cell cycle propagation is driven by light-dark stimulation in a cultured symbiotic dinoflagellate isolated from corals. Coral Reefs, 2008, 27: 823-835

17 Reimer J D, Takishita K, Ono S, et al. Latitudinal and intracolony ITS-rDNA sequence variation in the symbiotic dinoflagellate genus Symbiodinium (Dinophyceae) in Zoanthus sansibaricus (Anthozoa: Hexacorallia). Phycol Res, 2006, 54: 122-132

18 Chen C S. Phorbol ester induces elevated oxidative activity and alkalization in a subset of lysosomes. BMC Cell Biol, 2002, 3: 21

19 Franklin D J, Hoegh-Guldberg O, Jones R J, et al. Cell death and degeneration in the symbiotic dinoflagellates of the coral Stylophora pistillata during bleaching. Mar Ecol Prog Ser, 2004, 272: 117130

20 Royall J A, Ischiropoulos H. Evaluation of 2',7'-dichlorofluorscin and dihydrorhodamine 123 as fluorescent probes for intracellular $\mathrm{H}_{2} \mathrm{O}_{2}$ in cultured endothelial cells. Arch Biochem Biophys, 1993, 302: 348355

21 Collen J, Davison I R. In vivo measurement of active oxygen production in the brown alga Fucus evanescens using $2^{\prime}, 7^{\prime}$-dichlorohydrofluorescein diacetate. J Phycol, 1997, 33: 643-648

22 Beer S, Ilan M, Eshel A, et al. Use of pulse amplitude modulated (PAM) fluorometry for in situ measurements of photosynthesis in two Red Sea faviid corals. Mar Biol, 1998, 131: 607-612

23 Bligh E G, Dyer W J. A rapid method of total lipid extraction and purification. Can J Biochem Physiol, 1959, 37: 911-917

24 White T, Bursten S, Federighi D, et al. High-resolution separation and quantification of neutral lipid and phospholipid species in mammalian cells and sera by multi-one-dimensional thin-layer chromatography. Anal Biochem, 1998, 258: 109-117

25 Chen C S, Martin O C, Pagano R E. Changes in the spectral properties of a plasma membrane lipid analog during the first seconds of endocytosis in living cells. Biophys J, 1997, 72: 37-50

26 Maier O, Oberle V, Hoekstra D. Fluorescent lipid probes: some properties and applications (a review). Chem Phys Lipids, 2002, 116: 3-18

27 Berglund D L, Taffs R E, Robertson N P. A rapid analytical technique for flow cytometric analysis of cell viability using calcofluor white M2R. Cytometry, 1987, 8: 421-426

28 Hughes J, McCully M E. The use of an optical brightener in the study of plant structure. Stain Technol, 1975, 50: 319-329

29 Fritz L, Triemer R E. A rapid simple technique utilizing Calcofluor White M2R for the visualization of dinoflagellate thecal plates. J Phycol, 1985, 21: 662-664

30 Kwok A C M, Wong J T Y. Cellulose synthesis is coupled to cell cycle progression at $\mathrm{G}_{1}$ in the dinoflagellate Crypthecodinium cohnii. Plant Physiol, 2003, 131: 1681-1691

31 Oku H, Yamashiro H, Onaga K, et al. Lipid distribution in branching coral Montipora digitata. Fish Sci, 2002, 68: 517-522

32 Grottoli A G, Rodrigues L J, Juarez C. Lipids and stable carbon isotopes in two species of Hawaiian corals, Porites compressa and Montipora verrucosa, following a bleaching event. Mar Biol, 2004, 
145: 621-631

33 Koval M, Pagano R E. Lipid recycling between the plasma membrane and intracellular compartments: transport and metabolism of fluorescent sphingomyelin analogues in cultured fibroblasts. J Cell Biol, 1989, 108: 2169-2181

34 Muscatine L, Hand C. Direct evidence for the transfer of materials from symbiotic algae to the tissues of a coelenterate. Proc Natl Acad Sci USA, 1958, 44: 1259-1263

35 Baghdasarian G, Muscatine L. Preferential expulsion of dividing algal cells as a mechanism for regulating algal-cnidarian symbiosis. Biol Bull, 2000, 199: 278-286

36 Douglas A E. Coral bleaching-how and why? Mar Pollut Bull, 2003, 46: 385-392

37 Furla P, Allemand D, Shick J M, et al. The symbiotic anthozoan: a physiological chimera between alga and animal. Integr Comp Biol, 2005, 45: 595-604

38 Rinkevich B. Marine invertebrate cell cultures: new millennium trends. Mar Biotech, 2005, 7: 429-439

39 Richier S, Furla P, Plantivaux A, et al. Symbiosis-induced adaptation to oxidative stress. J Exp Biol, 2005, 208: 277-285

40 Mason W T. Isolation and characterization of the lipids of the sea anemone, Metridium senile. Biochim Biophys Acta, 1972, 280: 538-
544

41 London M, London E. Ceramide selectively displaces cholesterol from ordered lipid domains (rafts): implications for lipid raft structure and function. J Biol Chem, 2004, 279: 9997-10004

42 Klein U, Gimpl G, Fahrenholz F. Alteration of the myometrial plasma membrane cholesterol content with $\beta$-cyclodextrin modulates the binding affinity of the oxytocin receptor. Biochemistry, 1995, 34: 13784-13793

43 Neufeld E B, Cooney A M, Pitha J, et al. Intracellular trafficking of cholesterol monitored with a cyclodextrin. J Biol Chem, 1996, 271: 21604-21613

44 Huang H J, Wang L H, Peng S E, et al. New cell model for endosymbiosis research: spontaneous dissociation of endoderm cells based on tissue polarity in coral. Platax, 2007, 4: 9-25

45 Peng S E, Luo Y J, Huang H J, et al. Isolation of tissue layers in hermatypic corals by $\mathrm{N}$-acetylcysteine: morphological and proteomic examinations. Coral Reefs, 2008, 27: 133-142

46 Salih A, Larkum A, Cox G, et al. Fluorescent pigments in corals are photoprotective. Nature, 2000, 408: 850-853

47 Helmuth B S T, Timmerman B E H, Sebens K P. Interplay of host morphology and symbiont microhabitat in coral aggregations. Mar Biol, 1997, 130: 1-10

Open Access This article is distributed under the terms of the Creative Commons Attribution License which permits any use, distribution, and reproduction in any medium, provided the original author(s) and source are credited. 